www.scielo.cl

\title{
Síndrome Hemolítico Urémico asociado a Shigatoxina: ¿Cómo prevenirlo?
}

\author{
Shiga-toxin associated hemolytic uremic syndrome: How to prevent it?
}

\author{
Felipe Cavagnaro SM ${ }^{\mathrm{a}}$
}

aNefrólogo pediátrico, Clínica Alemana de Santiago, Facultad de Medicina Clínica Alemana-Universidad del Desarrollo.

Recibido el 11 de enero de 2019; aceptado el 5 de febrero de 2019

\begin{abstract}
Resumen
El síndrome hemolítico urémico (SHU) asociado a infección intestinal por bacterias productoras de Shigatoxina, que afecta principalmente a población infantil, puede causar morbilidad aguda grave, secuelas crónicas en varios órganos, y la muerte prematura en algunos de ellos. Dado su carácter zoonótico, adecuadas medidas de manejo agropecuario y correcta higiene de lo que consumimos es indispensable a la hora de prevenir la infección. Actualmente, una vez gatillado el SHU el manejo es médico y, principalmente, de soporte. En los últimos años diversas estrategias terapéuticas se han ido desarrollando para evitar que esta enfermedad ocurra, o, al menos, que pueda ser atenuada en sus consecuencias de morbi-mortalidad. El presente artículo describe acciones específicas a diferentes niveles de prevención de esta patología.
\end{abstract}

\begin{abstract}
Hemolytic uremic syndrome (HUS) associated with intestinal infection by Shiga toxin-producing bacteria, which mainly affects children, can cause severe acute morbidity, chronic sequelae in several organs, and premature death in some of them. Given its zoonotic nature, adequate measures of agricultural management and proper hygiene of what we consume are essential to prevent infection. Once the HUS is triggered, medical management is currently mainly supportive. In recent years, various therapeutic strategies have been developed to prevent this disease from occurring or, at least, to mitigate its morbidity and mortality consequences. This article describes specific actions at different levels of prevention of this pathology.
\end{abstract}

Palabras clave: Síndrome hemolítico urémico; SHU;

Prevención; E. coli O157:H7; Salud pública

\section{Keywords:}

Hemolytic uremic syndrome; HUS; Prevention; E. coli O157:H7; Public health 


\section{Introducción}

El síndrome hemolítico urémico (SHU), caracterizado por la tríada de anemia hemolítica microangiopática, trombocitopenia y daño renal agudo, es una enfermedad sistémica que pertenece a la familia de las microangiopatías trombóticas (MAT) y su etiología es multicausal, siendo la relacionada a infección intestinal por la bacteria Escherichia coli enterohemorrágica (ECEH), especialmente el serotipo O157:H7 productora de la toxina Shiga $[\mathrm{STx}(+)]$, por lejos la más frecuente en edad pediátrica ${ }^{1}$. En nuestro país, el SHU $\mathrm{STx}(+)$ afecta principalmente a niños entre los 6 meses y los 4 años y tiene una mortalidad cercana al $3 \%{ }^{2}$. Alrededor del 15\% de los pacientes infectados por ECEH, usualmente evidenciado clínicamente por dolor abdominal y deposiciones diarreicas con sangre, desarrollan un $\mathrm{SHU}^{3}$, y de estos últimos, alrededor de un $30 \%$ pueden presentar compromiso extra-renal importante (ej. infartos cerebrales, pancreatitis, necrosis colónica) o evolucionar hacia un daño renal crónico progresivo ${ }^{3,4}$.

En el contexto de la frecuencia y gravedad de esta patología, y de que por el momento no se dispone de un tratamiento específico para atenuar los efectos de esta enfermedad una vez que esta se ha declarado, los esfuerzos más importantes deben abocarse a su prevención. En este sentido, es necesario informar a la comunidad médica y obviamente a nuestros pacientes, sobre medidas y estrategias tendientes a evitar el SHU STx $(+)$ en nuestro medio. Para ello, en primer lugar describiremos las características del agente causal y luego se discutirán alternativas de prevención a diferentes niveles de acción.

\section{El agente}

El serotipo O157:H7 de la ECEH no es el único capaz de producir un SHU, pero es por lejos el más frecuente. Su patogenicidad radica especialmente, aunque no únicamente, en producir una familia de toxinas (STx) capaces de causar un daño letal a las células endoteliales de muchos tejidos, especialmente de riñón, cerebro y páncreas, y produciendo un fenómeno trombótico con la consecuente isquemia distal (MAT) $)^{3,5}$. Diversos estudios localizan el reservorio natural de esta bacteria principalmente en el intestino de los animales sanos de granja, especialmente los bovinos (vacunos), aunque también, en menor medida, en caprinos, porcinos, ovinos y otros animales, incluyendo animales salvajes y mascotas domésticas ${ }^{6}$. Esto último explica que el SHU sea más frecuente en población rural que urbana. Se han descrito casos de portadores humanos sanos $^{7}$. La ECEH resiste bastante bien las condiciones del medio ambiente natural -crece en forma óptima entre los 30 y $42^{\circ} \mathrm{C}$-, tolerando incluso temperaturas de congelación y el pH ácido del estómago, pero se inac- tiva y destruye con temperaturas mayores a $68^{\circ} \mathrm{C}^{8,9} . \mathrm{Su}$ supervivencia alcanza hasta los 60 días en materia fecal y algunas cepas hasta 104 días en un medio acuático ${ }^{10}$. Su baja dosis infectante $(<100 \mathrm{UFC} / \mathrm{g})$ le permite incluso causar infección sin necesidad de multiplicarse en los alimentos ${ }^{9,11}$.

\section{Prevención primaria. ¿Cómo evitamos la infección por ECEH?}

Dado los antecedentes recién mencionados, parece de vital importancia un correcto manejo agropecuario de animales de cuya carne y otros productos nos alimentamos. En este sentido hay evidencias que apoyan el uso de vacunaciones, modificación de tipo de alimentos (más granos que forraje), uso de probióticos, uso de bactericidas (clorato de sodio), solarización del suelo/camas secas/higiene de bebederos, separación de grupos de riesgo (animales jóvenes son más portadores de ECEH) y un adecuado procesamiento de estos en las plantas faenadoras ${ }^{6}$.

Así como evitamos que la masa ganadera se colonice por ECEH, el siguiente paso es evitar que esa bacteria llegue a nosotros desde los reservorios animales. Para ello debemos preocuparnos de evitar ingerir alimentos contaminados, aguas contaminadas, contacto con animales de riesgo y transmisión persona a persona con personas infectadas (Anexo 1).

- Alimentos contaminados. En este punto es importante diferenciar 3 tipos de alimentos: a) la carne u órganos comestibles de animales colonizados, lo cual se produce especialmente por mal manejo en las faenas del matadero, contaminando todo con contenido intestinal del animal. b) la leche o productos lácteos derivados de estos animales, y c) alimentos, especialmente vegetales, contaminados con deposiciones de animales colonizados o regados/lavados con aguas contaminadas por estos mismos animales.

- Aguas contaminadas. Algunas veces las deposiciones de animales pueden contaminar cursos de aguas (arroyos, ríos) y lugares de aguas quietas como pozos, tranques y lagunas, por lo que nadar en ellas, y especialmente beber esas aguas, puede ser de gran riesgo. Algo similar ha sido descrito con piscinas públicas y privadas, especialmente aquellas insuficientemente cloradas ${ }^{6}$. A su vez, se debe evitar que niños con diarrea se bañen con otros niños.

- Contacto con animales. Al visitar ferias ganaderas o granjas de animales se debe evitar tocar animales y menos besarlos. Los niños no debiesen estar comiendo o bebiendo durante esa actividad. Es necesario un buen lavado de manos con agua y jabón posterior a tocar animales u otras superficies cercanas a ellos, o antes de ingerir alimentos o líquidos en esos lugares. Se debiese realizar una adecuada 
limpieza de ropas y especialmente calzado posterior a estas visitas ${ }^{6,8}$.

- Transmisión persona a persona. Las personas infectadas por ECEH presentan un alto riesgo de contagiar a otras a través de sus deposiciones. Los niños infectados no deben asistir a sus actividades habituales (jardín infantil, colegio), y sus pañales adecuadamente eliminados; en ellos se debe supervisar un buen lavado de manos.

Aquellos pacientes que han presentado SHU deben tener, idealmente, al menos 2 coprocultivos negativos para poder reingresar a los establecimientos educacionales o guarderías. En el caso de pacientes hospitalizados, se debe instalar un aislamiento de contacto para evitar la transmisión directa (de un paciente a otro, a visitas o al personal de salud) o indirecta a través de objetos inanimados y, lo más importante el correcto lavado de manos del personal de salud ${ }^{6,12}$.

\section{Prevención secundaria. ¿Cómo evitamos el SHU si ya tenemos la infección por ECEH?}

Ante un cuadro clínico sugerente de infección por ECEH (especialmente diarrea con sangre más dolor abdominal importante) es de enorme importancia contar con métodos diagnósticos rápidos que nos certifiquen el agente causal en el menor tiempo posible, entendiendo que el resultado de un coprocultivo en agar sorbitol MacConkey (estándar dorado) tarda más de 48 horas en concluir un resultado. En nuestro país, existe una vigilancia nacional para laboratorios en la detección de infecciones causadas por $E$. coli productoras de $\operatorname{STx}(+)^{13}$.

En la actualidad se dispone de test de laboratorios rápidos en muestras de deposiciones, comercialmente disponibles, con variables grados de sensibilidad dada la corta duración de la STx en materia fecal ${ }^{8}$ :

- Metodologías genéticas: Reacción de Polimerasa en Cadena (PCR) múltiplex buscando genes de los principales factores de virulencia, principalmente las STx. También técnicas de hibridización de DNA - Metodologías Inmunológicas: inmunoensayos del tipo ELISA.

- Uso de antibióticos. Si bien varios estudios han mostrado una mayor incidencia de SHU STx $(+)$ al usar antibióticos en el tratamiento de las colitis por $\mathrm{ECEH}^{14,15}$, este tema es aún controversial y no demostrado en estudios de meta análisis ${ }^{16}$. Para efectos de decisiones, parece razonable seguir lo que aconseja el Centro de Control de Enfermedades de EE.UU que argumenta que existiendo el riesgo de producir un SHU con el uso de antibióticos y que no se ha demostrado un beneficio en la evolución del SHU con ellos, se desaconseja usarlos ${ }^{17}$.
- Uso de agentes que disminuyan motilidad intestinal. Este tipo de drogas, que incluye a fármacos como loperamida, anticolinérgicos y opiáceos, están contraindicados en pacientes con diarrea por ECEH, ya que podrían contribuir a la retención de STx en el colon y con ello aumentar el tiempo en el cual pueda absorberse la STx, aumentando el riesgo de desarrollar $\mathrm{SHU}^{18}$.

- Uso de quelantes intestinales de STx. El uso de sustancias que logran unirse y neutralizar a las STx en el lumen intestinal (Ej.Synsorb-Pk ${ }^{\odot}$ ) suscitaba una promisoria alternativa terapéutica, pero su resultado ha sido poco útil, aparentemente porque su uso en las infecciones por bacterias productoras de STx suele ser tardío, y ya se han absorbido suficientes toxinas como para gatillar la $\mathrm{MAT}^{6,19}$.

- Uso de expansión de volumen intravascular. Si bien es intuitivo evitar la deshidratación de estos pacientes para no agregar un factor prerrenal a una posible MAT que involucre a la irrigación intrarrenal, la expansión temprana y generosa del volumen vascular con solución fisiológica también ha mostrado disminuir la incidencia de compromiso renal de SHU en niños con diarrea por $\mathrm{ECEH}^{20}$.

\section{Prevención terciaria. ¿Cómo evitamos que el SHU tenga peor pronóstico?}

Existe poca claridad en relación a qué factores hacen que un SHU tenga una evolución más grave una vez que éste ya ha comenzado. Por tratarse de una patología con una patogenia principalmente trombótica, se intentaron diversas alternativas con tratamientos anticoagulantes (aspirina, heparina, urokinasa, dipiridamol) sin resultados alentadores, y aumentando el riesgo de sangrado ${ }^{21}$. Por otro lado, se debe recordar el evitar mayor daño renal no usando drogas nefrotóxicas (ej. Anti-inflamatorios no esteroidales) que sean prescindibles, y, si no se pueden dejar de usar en algunos casos (ej. Aminoglicósidos), monitorizar sus niveles plasmáticos si es posible, y mantenerlos en rango terapéutico. La plasmaféresis o la infusión de plasma fresco congelado en SHU STx $(+)^{21,22}$ es aún debatido y su eficacia no es apoyada por estudios randomizados, como si ocurre en otras MAT (SHU atípico, púrpura trombocitopénico trombótico adquirido ${ }^{23,24}$. De la misma manera, el uso de eculizumab, un anticuerpo monoclonal humanizado que detiene la cascada del complemento bloqueando el clivaje de C5, ha demostrado su utilidad en el SHU atípico por defectos genéticos o adquiridos de inhibidores de la cascada del complemento, pero en el caso del SHU STx(+) su eficacia no ha sido concluyentemente demostrada hasta el momento ${ }^{25}$, aunque sí parece tener cierta utilidad en disminuir las consecuencias neurológicas de esta patología ${ }^{26}$. 
Como fue mencionado antes, la expansión de volumen con infusión de solución salina puede mejorar el compromiso renal de pacientes con SHU.

\section{¿Qué viene a futuro en prevención de SHU?}

Por tratarse de una enfermedad zoonótica en su origen, la prevención del contagio debe partir por establecer normas agropecuarias y de higiene como las descritas antes. Pero mientras estas medidas no estén lo suficientemente implementadas, y dada las consecuencias agudas y crónicas, su significativa mortalidad, y los altos costos que implica su tratamiento, parece indispensable buscar otras estrategias para reducir su impacto en la salud pública.

- Vacunas. Como suele ocurrir con una gran cantidad de patologías infecciosas humanas, las inmunizaciones activas suelen ser eficaces en la prevención de estas. En este sentido, se están desarrollando estudios clínicos y experimentales con vacunas contra las STx (STx 1 y 2) o contra los genes que las codifican, contra otros factores de virulencia bacteriana y/o componentes de la pared celular de la ECEH, o contra toda la bacteria usando microorganismos atenuados ${ }^{27,28}$.

- Administración intravenosa de anticuerpos. Su mayor desarrollo es en la forma de anticuerpos monoclonales humanizados contra la STx. Entre ellos destacan Shigamab $^{\circledR}$, una mezcla de dos anticuerpos monoclonales, dirigidos contra la subunidad A de STx2 y contra la subunidad B de STx1 y el Urtoxazumab, dirigido contra la subunidad B de STx2. Estos anticuerpos han demostrado ser seguros en estudios de Fase I realizados en adultos sanos. Sin embargo, hasta el momento no se han publicado datos concluyentes de estudios clínicos de Fase II $^{29,30}$. En Latinoamérica destaca el trabajo de un grupo argentino que está desarrollando un antisuero en base a fragmentos F ( $\left.a b^{\prime}\right)$ de anticuerpos equinos contra STx 1 y 2, con buenos resultados preliminares en animales de experimentación ${ }^{31}$.

- Quelantes de toxinas en sangre. Se han desarrollados análogos del receptor celular de STx (Gb3) para administración parenteral, con mucho mayor afinidad que el Synsorb Pk. Entre ellos destaca Starfish ${ }^{\circledR}$ con afinidad por STx 1, Daisy ${ }^{\circledR}$ con mayor afinidad por STx 1 y 2, y Super Twigs ${ }^{\circledR}$ que permite quelar un mayor número de STx, formando complejos que pueden ser captados y degradados por macrófagos ${ }^{18}$. Ninguno de estos productos está por el momento disponible con fines comerciales.

\section{Conclusiones}

Las bacterias capaces de producir un SHU pueden estar presentes en muchos tipos de alimentos y objetos desde los cuales puede producirse el contagio a seres humanos. El intestino de animales de granja suele ser el principal reservorio de estos microorganismos patógenos, por lo que un correcto manejo agropecuario de estos produciría una disminución en la incidencia de SHU STx (+). Dado el contexto anterior, y a escala domiciliaria, el concepto de adecuada higiene, mantención de la cadena de frío y adecuada cocción de los alimentos que ingerimos es un elemento clave en la prevención de esta enfermedad. Una vez iniciada la infección intestinal la progresión hacia SHU es impredecible, aunque el uso de agentes que disminuyen la motilidad intestinal y eventualmente el uso de antibióticos podría influir en esta dirección. En este sentido, una rápida identificación de ECEH o STx en deposiciones permite tomar medidas terapéuticas y de aislamiento en forma precoz. Una buena sobrehidratación y evitar drogas nefrotóxicas parecen influir hacia una menor tasa de daño renal aguda grave. Una vez iniciado el cuadro clínico de SHU, el manejo clínico es actualmente, de soporte.

En un futuro cercano, además de lo anterior, también podremos disminuir la incidencia de infecciones por ECEH a través de vacunas y la progresión de esta infección hacia SHU por medio de la neutralización de las toxinas y otros factores de virulencia que gatillan esta grave enfermedad.

\section{Conflicto de intereses}

El autor declara no tener conflicto de intereses. 


\section{Anexo 1. Medidas de Prevención primaria de Infección por Escherichia coli enterohemorrágica (ECEH)}

\section{Para la compra y manipulación de los alimentos}

- Al realizar las compras, comience por los productos envasados y deje para el final los perecederos como carnes, aves, pescados o productos lácteos. No compre alimentos cocinados si han sido mantenidos cerca de alimentos crudos, aunque estén guardados en hielo

- Si compra carne picada, prefiera la que fue procesada en el momento y consúmala inmediatamente. Recuerde que este producto se alterará más rápidamente que una pieza de carne entera

- Controle las fechas de vencimiento de todos los productos. No compre alimentos sin fecha, marca o números de registro, ni aquellos cuyo envase se encuentre en malas condiciones: latas o tetrapack abollados o hinchados, o bolsas plásticas rotas

- No compre alimentos preparados que se exhiban a temperatura ambiente

- Los alimentos líquidos (lácteos, jugos) deben ser pasteurizados o bien hervidos previo consumo si no lo son

- No permita que le expendan el pan sin guantes o luego de haber manipulado dinero

- No compre huevos que tengan su cáscara rota o sucia

- Los productos como las carnes, aves y pescados deben guardarse en bolsas, separados de otros alimentos, para evitar que los jugos de los mismos puedan contaminarlos

- Si solicita el envío de mercadería a domicilio, asegúrese de que los productos perecederos permanezcan el menor tiempo posible a temperatura ambiente

\section{En el hogar}

- Al guardar la mercadería, coloque adelante los productos que venzan primero, a fin de consumirlos antes de que eso ocurra.

- Refrigere $\left(0 \mathrm{a} 4^{\circ} \mathrm{C}\right)$ lo antes posible las carnes (rojas y blancas) y otros perecibles luego de comprarlos, idealmente en recipientes sellados para que no escurra su jugo hacia otros alimentos. Congele $\left(0 \mathrm{a}-18^{\circ} \mathrm{C}\right)$ las carnes que no consumirá dentro de $48 \mathrm{~h}$

- No mezcle alimentos crudos y cocidos. Guarde en refrigerador y tapados aquellos alimentos que no van a ser sometidos al calor antes de ser ingeridos. De esta forma, prevendrá posibles contaminaciones con otros productos.

- Los alimentos cocinados "sobrantes" deben ser refrigerados dentro de 2 horas desde su cocción y guardados en recipientes separados. En caso de ser utilizados, deben ser recalentados a $>72^{\circ} \mathrm{C}$

- Lave las verduras y las frutas antes de ubicarlas en el refrigerador

- Al abrir una lata de conserva, transfiera todo el contenido a un envase de vidrio o de plástico. Nunca conserve el excedente en el envase original (lata)

- Conserve los huevos en el refrigerador y en su envase original, separados de otros alimentos listos para ser consumidos

- Higienice y descongele su refrigerador y/o freezer en forma semanal

\section{Durante la preparación de alimentos}

- Lavarse bien las manos con agua y jabón antes de cocinar y después de manipular carnes crudas, pescados y huevos

- No vuelva a congelar un alimento que ya fue descongelado, pues ello favorece la contaminación con microorganismos y su posterior proliferación. Descongele el producto en el refrigerador o en el microondas y no a temperatura ambiente, ni lo aproxime a una fuente de calor o bajo el chorro de agua caliente. Asegúrese de que, antes de cocinar el alimento, se haya completado su descongelación, sobre todo cuando se trata de piezas grandes

- Los preparados que contengan huevo crudo y las mezclas para preparar panqueques no deberán conservarse más de $24 \mathrm{~h}$

- No cocine verduras sin haberlas lavado previamente: la cocción puede destruir la contaminación microbiana presente pero no los contaminantes químicos (pesticidas, fertilizantes). Las frutas también deben ser lavadas cuidadosamente

- Si no posee agua potable de red controlada, hiérvala antes de usarla

- Evite la contaminación cruzada, utilizando distintos utensilios para manipular los alimentos crudos y los cocidos. Lávelos bien (cubiertos, platos, superficies) con agua y jabón o agua con cloro. Evitar tablas de madera

- En la cocción de carnes, lo ideal es usar un termómetro especial (insertable) para asegurar una temperatura interna $>a 72^{\circ} \mathrm{C}$. En el caso de pescados y mariscos, calentar hasta que carne esté firme, lo mismo con los huevos (yema y clara firmes) 


\section{Referencias}

1. Keir LS. Shiga Toxin Associated Hemolytic Uremic Syndrome. Hematol Oncol Clin N Am 2015;29:525-39.

2. Zambrano P, Delucchi A, Cavagnaro F, Hevia P, Rosati MP, Lagos E, y cols. Síndrome hemolítico urémico en Chile: presentación clínica, evolución y factores pronósticos. Rev Med Chile 2008;136:1240-6.

3. Cody E, Dixon B. Hemolytic uremic syndrome. Pediatr Clin N Am 2019;66:235-46.

4. Prado V, Cavagnaro F, y Grupo de Estudio de Infecciones por STEC. Síndrome hemolítico urémico asociado a infección por Escherichia coli productora de Shigatoxina (STEC) en pacientes chilenos: aspectos clínicos y epidemiológicos. Rev Chilena Infectol 2008;25:435-44.

5. Ibarra C, Goldstein J, Silberstein C, Zotta E, Belardo M, Repetto H. Síndrome urémico hemolítico inducido por Escherichia coli enterohemorrágica. Arch Argent Pediatr 2008;106:435-42.

6. Thomas D, Elliot E. Interventions for preventing diarrhea-associated hemolytic uremic syndrome: systematic review. BMC Public Health 2013;13:799-816.

7. Morita-Ishihara T, Iyoda S, Iguchi A, Ohnishi M. Secondary Shiga toxinproducing Escherichia coli infection, Japan, 2010-2012. Emerg Infect Dis. 2016;22:2181-4.

8. Newell DG, La Ragione RM. Enterohaemorrhagic and other Shiga toxin-producing Escherichia coli (STEC): Where are we now regarding diagnostics and control strategies? Transbound Emerg Dis 2018;65 Suppl 1: 49-71.

9. http://www.anmat.gov.ar/alimentos/ ficha_enfermedades_alimentos_SUH.pdf. Acceso 07/01/2019

10. Brusa V, Aliverti V, Aliverti F, Ortega E, de la Torre J, Linares L, et al. Shiga toxinproducing Escherichia coli in beef retail markets from Argentina. Front Cell Infect Microbiol 2013;2:171.

11. Obrig T. Escherichia coli Shiga toxin mechanism of actions in renal disease. Toxins 2010;2:2769-94.

12. Kintz E, Brainard J, Hooper L, Hunter P. Transmission pathways for sporadic Shiga-toxin producing E. coli infections: A systematic review and meta-analysis. Int J Hyg Environ Health 2017;220:57-67.
13. http://www.ispch.cl/sites/default/files/ documento/2017/07/Circular\%20 N\%C2\%B0\%2002\%20DEL\%20 14.07.2017\%20ISP\%20CIRCULAR\%20 VIGILANCIA\%20NACIONAL\%20 LAB.\%20ESCHERICHIA\%20COLI\%20 PRODUCTOR\%20TOXINA\%20 SHIGA\%20STEC.pdf. Acceso 07/01/2019.

14. Smith K, Wilker P, Reiter P, Hedican E, Bender J, Hedberg C. Antibiotic treatment of Escherichia coli O157 infection and the risk of hemolytic uremic syndrome, Minnesota. Pediatra Infect Dis J 2012;31:37-41.

15. Wong, C, Mooney J, Brandt J, Stapless A, Jelacic S, Boster D, et al. Risk factors for the hemolytic uremic syndrome in children infected with Escherichia coli O157:H7: a multivariable analysis. CID 2012;55:33-41.

16. Safdar N, Said A, Gangnon R, Maki D. Risk of hemolytis uremic syndrome after antibiotic treatment of Escherichia coli O157:H7 enteritis. JAMA 2002;288:9961001.

17. https://www.cdc.gov/ecoli/general/index. html. Acceso 07/01/2019.

18. NelsonJ, Griffin P, Jones T, Smith K, Scallan E. Antimicrobial and antimotility agent use in persons with Shiga toxinproducing Escherichia coli O157 Infection in FoodNet Sites. CID 2011;52:1130-2.

19. Palermo M, Exeni R, Fernández G. Hemolytic uremic syndrome: pathogenesis and Update of interventions. Expert Rev Anti Infect Ther 2009;7:697707.

20. Grisaru S, Xie J, Samuel S, et al. Associations between hydration status, intravenous fluid administration, and outcomes of patients infected with Shiga toxin-producing Escherichia coli: a systematic review and meta-analysis. JAMA Pediatr 2017;171:68-76.

21. Michael M, Elliott E, Ridley G, Hodson E, Craig J. Interventions for haemolytic uraemic syndrome and thrombotic thrombocytopenic purpura. Cochrane Database Syst Rev. 2009 Jan 21;(1):CD003595. doi: 10.1002/14651858. CD003595.pub2.

22. Keenswijk W, Raes A, De Clerck M, Vande Walle J. Is plasma exchange efficacious in Shiga toxin-associated hemolytic uremic syndrome? A narrative review of current evidence. Ther Apher Dial 2018 Oct 15. doi: 10.1111/17449987.12768.
23. Blombery P, Scully M. Management of thrombotic thrombocytopenic purpura: current perspectives. J Blood Med. 2014;5:15-23.

24. Winters JL. Plasma exchange in thrombotic microangiopathies (TMAs) other than thrombotic thrombocytopenic purpura (TTP). Hematology Am Soc Hematol Educ Program. 2017;2017: 632-8.

25. Walsh P, Johnson S. Eculizumab in the treatment of Shiga toxin haemolytic uraemic syndrome. Pediatr Nephrol 2018, published on line Jul 30. doi: 10.1007/ s00467-018-4025-0.

26. Giordano P, Netti GS, Santangelo L, Castellano G, Carbone V, Torres DD, et al. A pediatric neurologic assessment score may drive the eculizumab-based treatment of Escherichia coli-related hemolytic uremic syndrome with neurological involvement Pediatr Nephrol. 2018, published on line Oct 25. doi: 10.1007/s00467-018-4112-2

27. O'Ryan M, Vidal R, del Canto F, Salazar J, Montero D. Vaccines for viral and bacterial pathogens causing acute gastroenteritis: Part II: Vaccines for Shigella, Salmonella, enterotoxigenic E. coli (ETEC) enterohemorragic E. coli (EHEC) and Campylobacter jejuni. Human Vaccines \& Immunotherapeutics 2015;11: 601-19.

28. Rojas-López M, Monterio R, Pizza M, Desvaux M, Rosini R. Intestinal Pathogenic Escherichia coli: Insights for Vaccine Development. Front Microbiol 2018;9:440-56.

29. Bitzan M, Poole R, Mehran M, et al. Safety and pharmacokinetics of chimeric anti-shiga toxin 1 and antishiga toxin 2 monoclonal antibodies in healthy volunteers. Antimicrob Agents Chemother 2009;53:3081-7.

30. Moxley R,. Francis D, Tamura M, Marx D, Santiago-Mateo K, Zhao M. Efficacy of Urtoxazumab (TMA-15 humanized monoclonal antibody specific for Shiga toxin 2) against postdiarrheal neurological sequelae caused by Escherichia coli O157:H7 infection in the neonatal gnotobiotic piglet model. Toxins 2017; 9: 49 .

31. Hiriart $\mathrm{Y}$, Pardo R, Bukata L, Lauché C, Muñoz L, Colonna M, et al. Desarrollo de un producto anti-toxina Shiga para la prevención del síndrome urémico hemolítico. MEDICINA (Buenos Aires) 2018;78:107-12. 